\title{
Effectively Managing Type 1 Diabetes in Children - Education and Optimising New Technology
}

\author{
a report by \\ Thomas Danne ${ }^{1}$ and Olga Kordonouri ${ }^{2}$ \\ 1. Professor of Paediatrics, and Chief Physician; 2. Professor, and Senior Consultant, Department of General Paediatrics, \\ Children's Hospital 'Auf der Bult', Hannover DOI:10.17925/EE.2008.04.00.14
}

Recent developments indicate that the efforts of diabetes teams who are implementing approaches focused on age-appropriate education of patients, families and other care-givers in intensified insulin treatment in paediatric diabetes care have been successful. Also, the increased availability of continuous glucose sensors is likely to have a significant impact on paediatric diabetes therapy and education in the future. Families previously relying on self-monitoring blood glucose (SMBG) need to understand the difference between estimating the absolute blood glucose value (point accuracy) and the change in blood glucose (rate accuracy) and how to take into consideration the inherent interstitial time lag. The selection of patients capable and motivated to use continuous sensors accompanied with proper age-appropriate education remain important factors for the long-term success of these technological advances in diabetes therapy as long as closed-loop systems are not available.

\section{Treatment Targets in Paediatric Patients}

The Diabetes Control and Complications Trial (DCCT) and its follow-up, the Epidemiology of Diabetes Interventions and Complications (EDIC) study, confirmed that an improvement in long-term glucose control obtained with intensified insulin therapy can also reduce the incidence of complications and delay the progression of existing complications in type 1 diabetes in paediatric patients.1.2 Although only a subgroup of adolescents participated in the DCCT longitudinal studies in the paediatric population, such as the Berlin Retinopathy Study, they have revealed comparable results (see Figure 1). ${ }^{3}$ Reductions of glycated haemoglobin $\left(\mathrm{HbA}_{1 \mathrm{c}}\right)<9 \%$ lead to the most dramatic fall in the rate of retinopathy. Nevertheless, with every drop in $\mathrm{HbA}_{1 \mathrm{c}}$, lower rates of

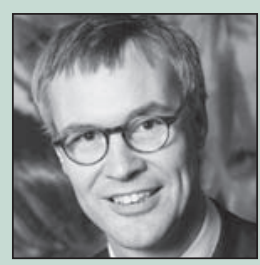

Thomas Danne is a Professor of Paediatrics and Chie Physician in the Department of General Paediatrics at Children's Hospital 'Auf der Bult' in Hannover. He is Secretary General and President Elect of the International Society for Pediatric and Adolescent Diabetes (ISPAD) and is a member of the Consultative Section for Childhood and Adolescent Diabetes (CSCAD) of the International Diabetes Federation (IDF). Professor Danne is also President Elect of the German Diabetes Association (DDG) and Deputy Editor of Pediatric Diabetes.

E: Danne@hka.de

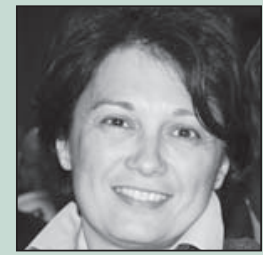

Olga Kordonouri is a Professor and Senior Consultant in Pediatrics and Diabetology at the Children's Hospital 'Auf der Bult' in Hannover. She was the convenor of the 2007 Annual Meeting of the International Society of Pediatric and Adolescent Diabetes (ISPAD) and is Secretary of the German Diabetes Association (DDG). She has received several scholarships and research grants, published numerous papers in the field and is Associate Editor of Pediatric Diabetes. retinopathy are achieved. Adolescents, particularly those with suboptimal control, should understand that a reduction of $\mathrm{HbA}_{1 \mathrm{c}}$, even if it is still significantly above the target of $7.5 \%$, is likely to have a major impact on their long-term prognosis when maintained over time. For each individual, the target should be the lowest achievable $\mathrm{HbA}_{1 c}$ without

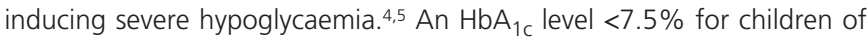
all ages - slightly above the target for adults - has been adopted by many paediatric diabetes centres.

\section{The Role of Glycaemic Variability in Paediatric Diabetes}

Currently, $\mathrm{HbA}_{1 \mathrm{c}}$ remains the gold standard for assessing the risk of late complications in paediatric patients; 6,7 however, it has obvious limits as it is only a parameter for average glucose levels. There is substantial variability in individual mean glucose concentrations for a given $\mathrm{HbA}_{1 \mathrm{c}}$ level. ${ }^{8}$ Evidence is building relating to the importance of glycaemic variability for various outcomes in type 1 diabetes. ${ }^{9}$ In patients with type 2 diabetes a significant association was reported between the mean amplitude of glycaemic excursions (MAGE), an established parameter for glycaemic variability, ${ }^{10}$ and urinary 8 -epimer of prostaglandin F2alpha (8-iso-PGF2 $\alpha$ ), a parameter related to superoxide overproduction and subsequent development of later complications. ${ }^{11}$ This suggests that different therapeutic strategies ${ }^{12}$ should be evaluated for their potential to minimise glycaemic excursion, as well as their ability to lower $\mathrm{HbA}_{1 \mathrm{c}}$. Therefore, wider use of realtime continuous glucose monitoring (CGM) in clinical practice would provide the required monitoring tool to minimise glycaemic variability. ${ }^{13} \mathrm{~A}$ new measure of glycaemia, derived from the duration of normal, low and high readings, could supplement $\mathrm{HbA}_{1 \mathrm{c}}$ as an integrated measure of control. Furthermore, measurements of MAGE, ${ }^{14}$ composite hypoglycaemic score $^{15}$ and lability index ${ }^{15}$ could provide information about the tendency for a mean blood glucose level to comprise stable or labile data points. For some patients, a decreased amount of glycaemic instability alone, even without any improvement in $\mathrm{HbA}_{1 \mathrm{c}}$, may represent an improved outcome.

\section{Paradigm Shift in Paediatric Diabetes Treatment}

There has been a recent paradigm shift in the treatment of paediatric diabetes. Previously, it was thought that the best way to overcome barriers to treating children would be to spare them from an insulin regimen consisting of many daily injections. Consequently, treatment consisted of two daily injections of pre-mixed insulins. This was accompanied by the need to follow a strict diet and daily schedule in order to match the insulin intake. Indeed, some centres are reporting good results with this approach. ${ }^{16}$ However, the majority of paediatric diabetologists now believe that the gold standard treatment for children with diabetes is intensified insulin therapy. Intensified insulin therapy aims to mimic as closely as possible the physiological insulin profile 
observed in non-diabetic individuals. This kind of regimen is also believed to allow the flexibility required with the lifestyle needs of children with diabetes. To match these challenges, the choice of rapid-, short-, intermediate- and long-acting insulins and insulin analogues (see Figure 2), as well as devices such as insulin pumps and glucose sensors, have led to many recent new developments in the treatment options for children with diabetes.

\section{Insulin Pump Therapy for Children}

Over the last decade, continuous subcutaneous insulin infusion (CSII) has increased in popularity among paediatric patients with diabetes. Theoretically, CSII offers the most physiological method of insulin delivery due to its ability to more closely simulate the normal pattern of insulin secretion, namely continuous 24-hour adjustable 'basal' delivery of insulin superimposed with prandial-related 'boluses'. In addition, CSII offers more flexibility and more precise insulin delivery than multiple daily injections (MDIs). Although randomised, controlled trials in young children have not yielded the same beneficial effects as the nonrandomised paired comparison studies, it is incorrect to conclude that paediatric pump therapy offers no real advantages to MDIs. ${ }^{17,18}$ The results of the large European Pedpump data collection indicate the safety of pumps for all age groups and document the flexibility of CSII, with many children taking seven or more daily prandial or correction boluses. ${ }^{19,20}$ The low rate of hypoglycaemia makes pumps an attractive choice, particularly for pre-school children. ${ }^{21}$ Poor motivation and support leading to a low number of boluses or not following the rules for preventing diabetic ketoacidosis (DKA) in CSII may lead to adverse outcomes. This may be a caveat to prescribing $\mathrm{CSIII}^{17}$ and it highlights the importance of individualising the decision as to the modality of therapy according to developmental stage and tasks.

\section{Insulin Analogues}

Insulin analogues are safe for use in paediatric patients. As pre-prandial insulin treatment is often problematic in young children with unpredictable and irregular eating habits, the post-prandial injection of rapid-acting insulin analogues offers the ease of adjusting the administration time and dosage according to mealtime and the size of the meal in injection therapy and CSII. In accordance with the pharmacokinetic results obtained in adults, insulin aspart and insulin glulisine were rapidly absorbed and eliminated in paediatric patients also. ${ }^{22,23}$ Post-prandial administration of insulin aspart was shown to be a safe and effective alternative to pre-prandial administration in a study of 76 children and adolescents, ${ }^{24}$ as well as in a trial of pre-school children two to six years of age..$^{25}$ Insulin suspensions with protamine (NPH) or zinc have been used for several years for delaying insulin action for basal insulin substitution. In most countries, the two basal analogues - insulin glargine and detemir - have not been formally approved for children below six years of age. However, there are reports of successful use of glargine in children from under one to five years of age. ${ }^{26}$ Randomised and observational studies with insulin glargine as the basal insulin have also shown reductions in nocturnal hypoglycaemia. ${ }^{27,28}$ In a six-month multicentre trial, 347 children (aged six to 17 years) with type 1 diabetes received comparable doses of insulin detemir or NPH insulin plus pre-meal insulin aspart. ${ }^{29}$ At followup, mean $\mathrm{HbA}_{1 \mathrm{c}}$ decreased by approximately $0.8 \%$ to $8 \%$ in both treatment groups, but children in the insulin detemir group had a significant $26 \%$ reduction in nocturnal hypoglycaemia compared with $\mathrm{NPH}$ insulin. In another cross-over study of 68 adolescents comparing
Figure 1: Continuous Exponential Relationship Between Background Retinopathy and Long-term Glycated Haemoglobin in Young Adults with Type 1 Diabetes

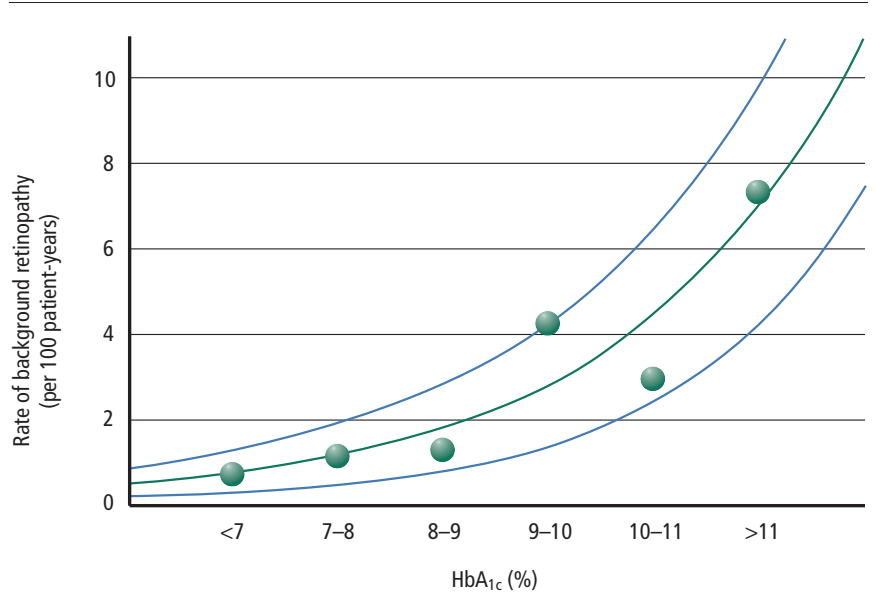

Relationship of median annual glycated haemoglobin ( $\mathrm{HbA}_{1}$ ) at onset of diabetes in 346 children with type 1 diabetes (190 males, 156 females, with an average age at onset of nine years) studied prospectively with repeated retinal fluorescein angiographies at intervals of one to two years in the Berlin Retinopathy Study; 19.8 (8.8-35.4) years of age; diabetes duration of 10.4 (1.1-27.4) years at their latest eye examination, median (range). Source: Data taken with permission from Danne et al. ${ }^{3}$

\section{Figure 2: Changes in Insulin Therapy 1986-2007}

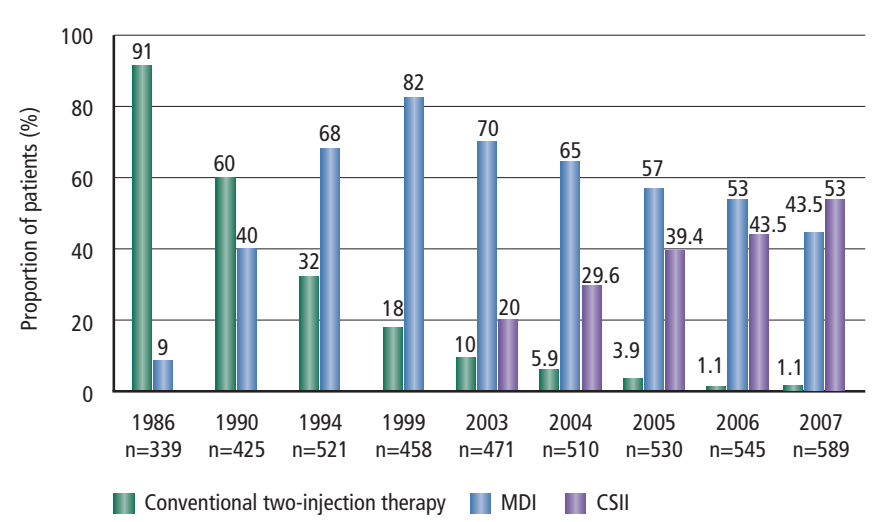

Changes from conventional two-injection therapy to intensified insulin therapy multiple daily insulin injection (MDI) and continuous subcutaneous insulin infusion (CSII) at Children's Hospital 'Auf der Bult', Hannover.

the bedtime injection of semilente zinc-insulin with insulin detemir, both insulins were equally effective in terms of the fasting plasma glucose levels. Despite an average 1.7-fold higher insulin dose to achieve the fasting blood glucose target, the incidence of mild and severe night-time hypoglycaemia was lower with detemir. ${ }^{30}$ Compared with $\mathrm{NPH}$, insulin detemir is also associated with less weight gain or weight reduction in paediatric patients ${ }^{29}$ and less variability. ${ }^{31}$

New Approaches in Educational and Psychosocial Concerns Ideally, a child with diabetes should have access to a specialised multidisciplinary team of diabetes healthcare professionals, including a paediatric diabetologist, a diabetes nurse educator and a dietician, as well as additional access to a psychologist, social worker and others. In many countries, age-appropriate educational programmes have been developed and evaluated for efficacy. The diabetes healthcare team will require special skills to accommodate patients based on the age of the child, level of comprehension and education of the child and his or her family and be capable of dealing with language and cultural needs that vary demographically. Recently, a mobile diabetes education and care 


\section{Current Issues}

team was shown to be effective in improving the quality of care in children with type 1 diabetes who have limited access to specialised diabetes care in rural areas. ${ }^{32}$ Regardless of the insulin regimen prescribed, frequency of SMBG correlates with improved glucose control and increased treatment adherence. ${ }^{33}$ Historically, youths were encouraged towards independence in diabetes care, but recent studies indicate that premature withdrawal of parents from diabetes care is associated with adverse outcomes. ${ }^{34}$ Support from school and day care is also important in the management of diabetes in this age group because many children require insulin with lunch or at other times when they are away from home. ${ }^{35}$ The social and professional integration of parents - particularly mothers - with younger children at the onset of diabetes needs to be improved through support measures outside the family. In a recent survey of 580 German families, $31 \%$ of mothers reduced their working time or stopped working and $33 \%$ of mothers reported handicaps in their professional career development, especially those with a child with age at onset below six years (44\%). Negative financial consequences were observed in $44 \%$ of the families. ${ }^{36}$ Patient and family education and close contact with the diabetes team are associated with reduced hospitalisations and emergency room visits and improvements in glycaemic control, ${ }^{37}$ and additional telephone contacts may be beneficial. ${ }^{38}$

\section{Retrospective Glucose Sensors}

Education may also be the key to success for CGM. Currently, three subcutaneous enzymatic sensors in four systems are available. They are the Continuous Glucose Monitoring System Gold (CGMS Gold, Medtronic MiniMed, Northridge, California), ${ }^{39}$ the Guardian Telemetered Glucose Monitoring System (Medtronic MiniMed), ${ }^{40}$ the FreeStyle Navigator Continuous Glucose Monitor (Abbott Laboratories, Alameda, California) ${ }^{41}$ and the DexCom STS. ${ }^{42}$ They differ in terms of needle length, sensor wear, number of calibrations and time from placement to display. The CGMS has been reported to serve as a tool to reveal daily glucose trends missed by SMBG, to serve as an educational tool to improve metabolic control and to decrease the rate and magnitude of hypoglycaemia in young patients with type 1 diabetes. ${ }^{43}$ Age does not appear to be a limiting factor, as these systems can be also applied in the pre-school group. ${ }^{44}$ However, a recent meta-analysis ${ }^{45}$ of five randomised paediatric studies ${ }^{46-50}$ indicated that the technology that allows a realtime assessment of glycaemia by the patient does not lead to a significant improvement of $\mathrm{HbA}_{1 \mathrm{c}}$, but only a retrospective analysis by the doctor will suffice. However, others have reported its usefulness in the management of individual patients, particularly adolescents experiencing difficulties with adherence to diabetes management and in detecting unrecognised hypoglycaemia. ${ }^{51}$ CGM can also be used to contrast the effectiveness of various therapeutic strategies in research settings. ${ }^{52}$ The power of CGM as a research tool was demonstrated in providing proof of the association of fluctuating blood glucose levels and behavioural changes that parents frequently report in their diabetic children. ${ }^{53}$

\section{The Realtime Sensors}

In contrast to the physician-based analysis of retrospective data of the Holter-type sensors, the realtime sensors shift the focus to the patient and the family, enabling them to react to subcutaneous glucose readings in a 'biofeedback' fashion. In a multicentre study with adult and paediatric participants, ${ }^{54}$ the efficacy of realtime CGM using the Guardian ${ }^{\circledR}$ RT system was evaluated in 81 children and adolescents with type 1 diabetes in whom glycaemic control was suboptimal despite intensive insulin therapy. The results of the study demonstrated that realtime CGM using the Guardian RT system improved glycaemic control compared with SMBG, especially in the group continuously using the system. ${ }^{54}$ The constant availability of glucose measurements permitted the patients to adjust their own insulin doses, food intake and physical activity and thus improve their glycaemic control. ${ }^{55} \mathrm{~A}$ pilot trial of one month in 10 type 1 diabetic children was reported in which the realtime CGM and the insulin pump were combined into a sensoraugmented pump system. ${ }^{56}$ The international, multicentre ONSET Trial will compare the effect of conventional CSII with sensor-augmented pump (SAP) therapy during the first year after onset of diabetes in 160 paediatric patients in a randomised, prospective trial. The ONSET trial will provide evidence for advocating this technology from the onset and thereby learn about diabetes in a feedback fashion. Paediatric experience is also available for the FreeStyle Navigator ${ }^{57}$ and the Dexcom STS. ${ }^{58}$ Improvements of $\mathrm{HbA}_{1 c}$ were seen with realtime CGM both in paediatric patients on a pump ${ }^{59}$ and those on MDI insulin regimens. ${ }^{60}$

\section{Educating Patients About the New Technology}

Teaching patients to determine how to utilise all the data provided by CGM remains a challenge. Families previously relying on SBGM need to understand the difference between estimating the absolute blood glucose value (point accuracy) and change in blood glucose (rate accuracy) and how to take into consideration the inherent interstitial time lag. All of the available sensors show a lower point accuracy compared with SMBG. However, a patient able to read trends in CGM will be able to live easily with this limitation when sufficient experience is gained in analysing glucose trends. Practical algorithms need to be developed to calculate the current and future insulin infusion/injection rates. Patient variability in assessing the glycaemic excursion of the meal may also affect the function of such an open-loop system. From the beginning it is critical to understand the reasons for delays between glucose changes and a displayed value. For reasons that are not completely understood, all subcutaneous sensors need a certain time after placement before they give a stable signal. Apparently, the trauma associated with subcutaneous insertion impairs glucose measurement for some time before reaching an equilibrium. Depending on the system, the 'blind period' between placement and display of values ranges from two to 10 hours. Even after an initial stable signal is reached, the reaction of the surrounding tissues with the sensor surface continues to lead to changes of the sensor signal over time ('drift'), and repeated calibration may allow adjustment for drift for a certain period. Patients need to understand that the glucose measurements are in the interstitial fluid, and the lag time between blood and interstitial fluid sampled glucose levels may be in the range of five to 10 minutes. Although accuracy is slightly improved with more calibrations, the timing of the readings appears more important. Modifying the algorithm to attach less importance to daytime calibrations for night-time values and calibrating during times of relative glucose stability may have a greater impact on accuracy. ${ }^{61}$

\section{Selecting the Right Patients for \\ Continuous Glucose Monitoring}

In addition to proper education, patient selection may be integral to CGM success, and the key to sensor success is the motivation to continuously use it. Early studies with the Glucowatch have shown more 
frequent use over a six-month period among youths whose parents reported higher scores for treatment adherence and diabetes-related quality of life at baseline. The study illustrates the empirical assessment of the psychological context of CGM use. ${ }^{62}$ In a recent study of SAP therapy in $40 \mathrm{CSII}$-experienced adolescents with $\mathrm{HbA}_{1 \mathrm{c}}>7.5 \%$, the improvement of $\mathrm{HbA}_{1 c}$ was closely related to use of a sensor. ${ }^{63}$ Therefore, psychological assessments about adherence to CGM may demonstrate the power of this technology much better that an uncritical application in unselected patients, not all of them using the information continuously. This observation is summed up in the phrase 'an expensive watch is not going to make you punctual unless you use it'.

\section{Closed Loop}

Several approaches are used in the search for an 'artificial pancreas', ${ }^{64-66}$ and the time lag remains one of the major obstacles on the road to such a concept. In a research centre setting, a meal detection algorithm studied in 19 one- to six-year-old children detected a meal at a mean time of 30 minutes from the onset of eating, at which time the mean serum glucose was $21 \mathrm{mg} / \mathrm{dl}$ above baseline (range $2-36 \mathrm{mg} / \mathrm{dl}$ ), although more than $90 \%$ of meals were detected before the glucose had risen $40 \mathrm{mg} / \mathrm{dl}$ from baseline. ${ }^{67}$ In combination with the delay of CSII, such a time lag remains a problem for automated insulin dosing in response to meals and ultimately the development of a closed-loop system.

\section{Improved Outcomes Through Target}

\section{Setting and Physiological Insulin Therapy}

At our institution, the change from former years from the conventional twice-daily regimen of a pre-mixed fixed mixture and, latterly, free mixing of soluble and isophane insulin to multiple dose injections and, more recently, insulin pumps has been associated with a continuous improvement of glycaemic control. This improvement also has to be seen in the context of improvements in patient education, self monitoring and the development of diabetes teams. Nevertheless, the role of age-appropriate education for children and adolescents with diabetes and their families with the principles of flexible, intensive insulin regimens with clear targets from the onset of type 1 diabetes should not be underestimated (see Figure 3). ${ }^{68}$ Such improvements with the introduction of multiple injection therapy have not been observed in all centres. ${ }^{69}$ It remains to be clarified in individual cases if daily management with four injections is a true intensive insulin management discriminating between the substitution of basal and prandial insulin needs or rather a conventional insulin therapy injecting insulin four times daily. In our experience, the imitation of the physiological ratio between prandial and basal insulin is a pre-requisite for near normoglycaemic metabolic control with MDIs or CSII in children and adolescents. ${ }^{70}$ The basal insulin to cover for the hepatic
Figure 3: Improvements of Glycaemic Control - Levels of Glycated Haemoglobin 1994-2007

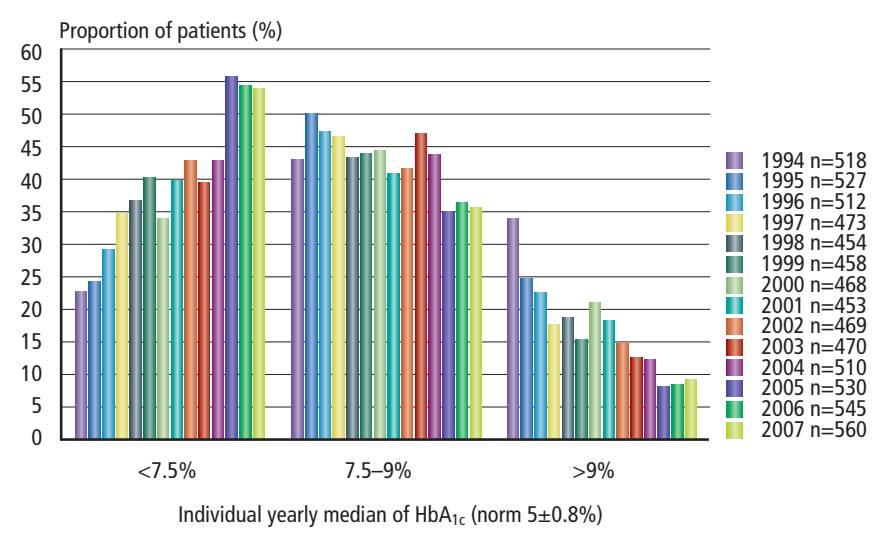

Data taken as part of the same study as Figure 2 at Children's Hospital 'Auf der Bult'.

gluconeogenesis should not be more than $30-40 \%$ of the total daily insulin, while the prandial insulin need is usually more than $50 \%$ of the total dose. Although the remarkable $\mathrm{HbA}_{1 \mathrm{c}}$ differences between centres are still present, in the international multicentre Hvidore collaboration for paediatric diabetes outcome quality studies it was identified that diabetes management concerns such as access to the diabetes team and, particularly, a setting of clear targets played a major role in the outcome. ${ }^{71}$

\section{Conclusions}

It is our prediction that in the next five to 10 years realtime CGM will become the standard of care for the treatment of paediatric patients with type 1 diabetes. ${ }^{72}$ However, in order to scientifically prove the promise of CGM in children with type 1 diabetes, appropriate randomised prospective studies assessing this new technology in selected patients are needed. Psychological evaluation may be important in identifying patients likely to wear a sensor continuously. If the $\mathrm{HbA}_{1 \mathrm{c}}$ is high at baseline it may be because families are not using the tools correctly, and, possibly, sensor technology may be better for those with only modest $\mathrm{HbA}_{1 \mathrm{c}}$ elevations. All in all, the emerging evidence for glycaemic variability playing a role in such different areas, i.e. behavioural changes of children and the development of vascular complications, underscores that additional end-points regarding $\mathrm{HbA}_{1 \mathrm{c}}$ need to be considered in future outcome studies. It is likely that with a better understanding of the molecular, medical and psychosocial mechanisms involved, the next advances in the treatment of children with all forms of diabetes are imminent. In the meantime, every effort should be made to investigate the long-term benefit of these recent new developments in paediatric diabetes.
1. The DCCT Research Group, The effect of intensive diabetes treatment on the development and progression of long-term complications in adolescents with insulin-dependent diabetes mellitus: the Diabetes Control and Complications Trial, J Pediatr, 1994;125(2):177-88.

2. DCCT/EDIC Research Group, Beneficial effects of intensive therapy of diabetes during adolescence: outcomes after the conclusion of the Diabetes Control and Complications Trial, J Pediatr, 2001;139(6):804-12.

3. Danne $T$, Weber $B$, Hartmann $R$, et al., Long-term glycemic control has a nonlinear association to the frequency of background retinopathy in adolescents with diabetes. Followup of the Berlin Retinopathy Study, Diabetes Care, 1994;17: 1390-96.
4. Hanas R, Donaghue K, Klingensmith G, Swift PG, International Society for Pediatric and Adolescent Diabetes (ISPAD) Clinical Practice Consensus Guidelines 2006-2007, Pediatr Diabetes, 2006;7(6):341-2.

5. National Institute for Clinical Excellence, Type 1 diabetes: diagnosis and management of type 1 diabetes in children, young people and adults, 2004. Available at: www.nice.org. uk/pdf/CG015NICEguideline.pdf

6. The DCCT Research Group, The effect of intensive diabetes treatment on the development and progression of long-term complications in adolescents with insulin-dependent diabetes mellitus: the Diabetes Control and Complications Trial, J Pediatr, 1994:125:177-88.

7. DCCT/EDIC Research Group, Beneficial effects of intensive therapy of diabetes during adolescence: outcomes after the conclusion of the Diabetes Control and Complications Trial, J Pediatr, 2001;139:804-12.

8. The Diabetes Research in Children Network (DirecNet) Study Group, The relationship of A1c to glucose concentrations in children with type 1 diabetes: Assessments by high frequency glucose determinations by sensors, Diabetes Care, 2007; Epub ahead of print.

9. Heller S, Kim H, Draeger E, Within-person variation in fasting blood glucose is correlated to incidence of hypoglycemia in people with type 1 diabetes treated with insulin detemir and NPH insulin, Diabetologia, 2004;47(Suppl. 1):A303.

10. Service FJ, Molnar GD, Rosevear JW, et al., Mean Amplitude of Glycemic Excursions, a Measure of Diabetic Instability, Diabetes, 


\section{Current Issues}

1970;19:644-55.

11. Saudek CD, Derr RL, Kalyani RR, Assessing glycemia in diabetes using self-monitoring blood glucose and hemoglobin A1c, JAMA, 2006;295:1688-97.

12. Danne $\mathrm{T}$, Lange $\mathrm{K}$, Kordonouri $\mathrm{O}$, New developments in the treatment of type 1 diabetes in children, Arch Dis Child, 2007:92:1015-19.

13. Brownlee $M$, Hirsch IB, Glycemic variability: a hemoglobin A1C independent risk factor for diabetic complications, JAMA, 2006 295:1707-8.

14. Alemzadeh R, Loppnow C, Parton E, Kirby M, Glucose sensor evaluation of glycemic instability in pediatric type 1 diabetes mellitus, Diabetes Technol Ther, 2003;5:167-73.

15. Ryan EA, Shandro T, Green K, et al., Assessment of the severity of hypoglycemia and glycemic lability in type 1 diabetic subjects undergoing islet transplantation, Diabetes, 2004;53:955-62.

16. Dorchy $\mathrm{H}$, Dietary management for children and adolescents with diabetes mellitus: personal experience and recommendations, J Pediatr Endocrinol Metab, 2003;16: 131-48.

17. Phillip M, Battelino T, Rodriguez $\mathrm{H}$, et al., Consensus Statement on the Use of Insulin Pump Therapy in the Pediatric Age-Group, Diabetes Care, 2007;30(6):1653-62.

18. Nimri $R$, Weintrob $N$, Benzaquen $H$, et al., Insulin pump therapy in youth with type 1 diabetes: a retrospective paired study, Pediatrics, 2006;117(6):2126-31.

19. Danne T, Battelino T, Kordonouri O, et al., A cross-sectional international survey of continuous subcutaneous insulin infusion in 377 children and adolescents with type 1 diabetes mellitus from 10 countries, Pediatr Diabetes, 2005;6(4):193-8.

20. Danne $T$, Battelino $T$, Jarosz-Chobot $P$, et al., for the PedPumpStudy Group, Establishing glycaemic control with continuous subcutaneous insulin infusion in children and adolescent with type 1 diabetes: experience from the PedPump Study in 17 countries, Diabetologia, 2008; in press.

21. Weinzimer SA, Ahern JH, Doyle EA, et al., Persistence of benefits of continuous subcutaneous insulin infusion in very young children with type 1 diabetes: a follow-up report, Pediatrics, 2004;114(6):1601-5.

22. Mortensen H, Lindholm A, Olsen B, Hylleberg B, Rapid appearance and onset of action of insulin aspart in paediatric subjects with type 1 diabetes, Eur J Pediatric, 2000;159:483-8.

23. Danne T, Becker RH, Heise T, et al., Pharmacokinetics, prandial glucose control, and safety of insulin glulisine in children and adolescents with type 1 diabetes, Diabetes Care, 2005;(9): 2100-2105.

24. Danne T, Aman J, Schober E, et al., A comparison of postprandial and pre-prandial administration of insulin aspart in children and adolescents with type 1 diabetes, Diabetes Care, 2003;26:2359-84

25. Danne T, Råstam J, Odendahl R, et al., Parental preference of Prandial Insulin Aspart compared to Preprandial Human Insulin in a Basal-bolus Scheme with NPH insulin in a Twelve Week Crossover-Study of Preschool Children with Type 1 Diabetes, Pediatr Diabetes, 2007;8:278-85.

26. Alemzadeh R, Berhe T, Wyatt DT, Flexible insulin therapy with glargine insulin improved glycemic control and reduced severe hypoglycemia among preschool-aged children with type 1 diabetes mellitus, Pediatrics, 2005;115(5):1320-24.

27. Chase HP, Dixon B, Pearson J, et al., Reduced hypoglycemic episodes and improved glycemic control in children with type diabetes using insulin glargine and neutral protamine Hagedorn insulin, J Pediatr, 2003;143(6):737-40.

28. Schrober E, Schoenle E, Can Dyk J, et al., Comparative trial between insulin glargine and NPH insulin in children and adolescents with type 1 diabetes mellitus, J Pediatr Endocrinol Metab, 2002;15(4):369-76.

29. Robertson K, Schönle E, Gucev Z, et al., Benefits of insulin detemir over NPH insulin in children and adolescents with type 1 diabetes: lower and more predictable fasting plasma glucose and lower risk of nocturnal hypoglycaemia, Diabet Med, 2005; 22(Suppl. 2):45 (abstract P66).

30. Kordonouri O, Datz N, Hoeffe J, et al., Efficacy and Safety of Bedtime Insulin Detemir vs. Insulin Semilente in Children, Adolescents, and Young Adults with Type 1 Diabetes. A Randomised, Open-Label, Cross-Over Study, Pediatr Diabetes, 2006 ; 7(Suppl. 5):68-9 (abstract).

31. Danne T, Lupke K, Walte $K$, et al., Insulin detemir is characterized by a consistent pharmacokinetic profile across age-groups in children, adolescents, and adults with type 1 diabetes, Diabetes Care, 2003;26:3087-92.

32. von Sengbusch S, Muller-Godeffroy E, Hager S, et al., Mobile diabetes education and care: intervention for children and young people with Type 1 diabetes in rural areas of northern Germany, Diabet Med, 2006;23:122-7.

33. Skinner TC, John M, Hampson SE, Social support and personal models of diabetes as predictors of self-care and well-being: a longitudinal study of adolescents with diabetes, J Pediatric Psychology, 2000;25:257-67.

34. Anderson B, Ho J, Brackett J, et al., Parental involvement in diabetes management tasks: relationships to blood glucose monitoring adherence and metabolic control in young adolescents with insulin-dependent diabetes mellitus, J Pediatr , 1997;130:257-65.

35. American Diabetes Association. Diabetes care in the schoo and day care setting (Position Statement), Diabetes Care, 2004;27 (Suppl. 1):S122-S128.

36. Lange K, Danne T, Kordonouri O, et al., Diabetes in childhood: everyday burden and professional consequences for parents, Disch Med Wochenschr, 2004:129(20):1130-34.

37. Svoren BM, Butler D, Levine BS, et al., Reducing acute adverse outcomes in youths with type 1 diabetes: a randomized, controlled trial, Pediatrics, 2003;112:914-22.

38. Howells $L$, Wilson AC, Skinner TC, et al., A randomized control trial of the effect of negotiated telephone support on glycaemic control in young people with type 1 diabetes, Diabet Med, 2002;19:643-8

39. Gross TM, Bode BW, Einhorn D, et al., Performance evaluation of the MiniMed continuous glucose monitoring system during patient home use, Diabetes Technol Ther, 2000;2:49-56.

40. Bode B, Gross K, Rikalo N, et al., Alarms based on real-time sensor glucose values alert patients to hypo- and hyperglycemia: the guardian continuous monitoring system, Diabetes Technol Ther, 2004;6:105-13.

41. Feldman B, Brazg R, Schwartz $S$, Weinstein R, A continuous glucose sensor based on wired enzyme technology: results from a 3-day trial in patients with type 1 diabetes, Diabetes Technol Ther, 2003;5:769-79.

42. Bailey TS, Zisser HC, Garg SK, Reduction in hemoglobin A1C with real-time continuous glucose monitoring: results from a 12-week observational study, Diabetes Technol Ther, 2007; 9:203-10.

43. Weintrob N, Schechter $A$, Benzaquen $H$, et al., Glycemic patterns detected by continuous subcutaneous glucose sensing in children and adolescents with type 1 diabetes mellitus treated by multiple daily injections vs. continuous subcutaneous insulin infusion, Arch Pediatr Adolesc Med, 2004;158:677-84.

44. Gandrud LM, Xing D, Kollman C, et al., The Medtronic Minimed Gold continuous glucose monitoring system: an effective means to discover hypo- and hyperglycemia in children under 7 years of age, Diabetes Technol Ther, 2007:9:307-16.

45. Golicki DT, Golicka D, Groele L, Pankowska E, Continuous Glucose Monitoring System in children with type 1 diabetes mellitus: asystematic review and meta-analysis, Diabetologia, 2008;51:233-40.

46. Yates K, Hasnat Milton A, Dear K, Ambler G, Continuous glucose monitoring-guided insulin adjustment in children and adolescents on near-physiological insulin regimens: a randomized controlled trial, Diabetes Care, 2006;29:1512-17.

47. Lagarde WH, Barrows FP, Davenport ML, et al., Continuous subcutaneous glucose monitoring in children with type diabetes mellitus: a single-blind, randomized, controlled trial, Pediatr Diabetes, 2006; 7:159-64.

48. Deiss D, Hartmann R, Schmidt J, Kordonouri O, Results of an randomized controlled cross-over-trial on the effect of continuous glucose monitoring (CGMS) on glycemic control in childen and adolescents with type 1 diabetes, Exp Clin Endocrino Diabetes, 2006;114:63-7.

49. Ludvigsson J, Hanas R, Continuous subcutaneous glucose monoitoring improved metabolic control in pediatric patients with type 1 diabetes: a controlled cross-over study, Pediatrics, 2003;111:933-8

50. Chase HP, Kim LM, Owen SL, et al., Continuous glucose monitoring in children with type 1 diabetes, Pediatrics, 2001; 107:222-6

51. Wiltshire EJ, Newton K, McTavish L, Unrecognised hypoglycaemia in children and adolescents with type diabetes using the continuous glucose monitoring system: prevalence and contributors, J Paediatr Child Health, 2006;42:758-63.

52. Deiss $D$, Kordonouri $O$, Hartmann $R$, et al., Treatment with insulin glargine reduces asymptomatic hypoglycemia detected by continuous subcutaneous glucose monitoring in children and adolescents with type 1 diabetes, Pediatr Diabetes, 2007;8: $157-62$.

53. McDonnell CM, Northam EA, Donath SM, Werther GA, Cameron FJ, Hyperglycemia and externalizing behavior in children with type 1 diabetes, Diabetes Care, 2007;30(9): 2211-15

54. Deiss D, Bolinder J, Riveline JP, et al., Improved glycemic control in poorly controlled patients with type 1 diabetes using real-time continuous glucose monitoring, Diabetes Care, 2006;29: 2730-32.

55. Tubiana-Rufi N, Riveline JP, Dardari D, Real-time continuous glucose monitoring using Guardian ${ }^{\circledR} \mathrm{RT}$ : from research to clinical practice, Diabetes Metab, 2007:33:415-20.

56. Halvorson M, Carpenter S, Kaiserman K, Kaufman F, A pilot trial in pediatrics with the sensor-augmented pump: combining real-time continuous glucose monitoring with the insulin pump,

J Pediatric, 2007:150:103-5.

57. Wilson DM, Beck RW, Tamborlane WV, et al., The accuracy of the FreeStyle Navigator continuous glucose monitoring system in children with type 1 diabetes, Diabetes Care, 2007;30:59-64.

58. Buckingham B, Caswell K, Wilson DM, Real-time continuous glucose monitoring, Curr Opin Endocrinol Diabetes Obes, 2007; 14:288-95.

59. Diabetes Research in Children Network (DirecNet) Study Group, Buckingham B, Beck RW, et al., Continuous glucose monitoring in children with type 1 diabetes, J Pediatr, 2007; 151:388-93, 393.e1-2.

60. Weinzimer S, Xing D, Tansey M, et al., Diabetes Research in Children Network (DirecNet) Study Group, FreeStyle NavigatorTM Continuous Glucose Monitoring System Use in Children with Type 1 Diabetes using glargine-based multiple daily dose regimens: Results of a Pilot Trial, Diabetes Care, 2008:31(3):525-7.

61. Diabetes Research In Children Network (Direcnet) Study Group, Buckingham BA, Kollman C, et al., Evaluation of factors affecting CGMS calibration, Diabetes Technol Ther, 2006;8(3): $318-25$.

62. Diabetes Research in Children Network (DirecNet) Study Group, Psychological aspects of continuous glucose monitoring in pediatric type 1diabetes, Pediatr Diabetes, 2006;7(1):32-8

63. Buckingham B, Halvorson M, Kunselman E, Kaufmann FR, Sensor augmented pump therapy in adolescents: results of the first treat-to-target study, Diabetes, 2007;56(Suppl. 1):A479.

64. Updike SJ, Shults MC, Gilligan BJ, Rhodes RK, A subcutaneous glucose sensor with improved longevity, dynamic range, and stability of calibration, Diabetes Care, 2000;23:208-14.

65. Renard E, Implantable closed-loop glucose-sensing and insulin delivery: the future for insulin pump therapy, Curr Opin Pharmacol, 2002;2(6):708-16.

66. Hovorka R, Chassin LJ, Wilinska ME, Closing the loop: The ADICOL experience, Diabetes Thechnol Ther, 2004;6(3):307-18.

67. Dassau E, Bequette BW, Buckingham BA, Doyle FJ, Detection of a Meal Using Continuous Glucose Monitoring (CGM): Implications for an Artificial \{beta\}-cell, Diabetes Care, 2008; 31(2):295-300.

68. Chase HP, Lockspeiser T, Peery B, et al., The impact of the diabetes control and complications trial and humalog insulin on glycohemoglobin levels and severe hypoglycemia in type 1 diabetes, Diabetes Care, 2001;24:430-44.

69. Danne T, Mortensen HB, Hougaard P, et al., For the Hvidore Study Group on Childhood Diabetes.Persistent differences among centers over 3 years in glycemic control and hypoglycemia in a study of 3,805 children and adolescents with type 1 diabetes from the Hvidore Study Group, Diabetes Care, 2001;24:1342-47.

70. Danne $T$, von Schutz $W$, Lange $K$, et al., Current practice of insulin pump therapy in children and adolescents - the Hannover recipe, Pediatr Diabetes, 2006;7(Suppl. 4):25-31.

71. Swift PGF, de Beaufort $C E$, Skinner $T C$, on behalf of the Hvidore Study Group Services provided by the diabetes team: do they effect the glycemic outcome?, Ped Diabetes, 2006;7 (Suppl. 5):19 (abstract).

72. Klonoff $D C$, Continuous glucose monitoring: roadmap for $21 \mathrm{st}$ century diabetes therapy, Diabetes Care, 2005;28:1231-9. 